\title{
Dexmedetomidine use and Mortality in Mechanically- Ventilated Patients with Severe Burns: A Cohort Study Using a National Inpatient Database in Japan
}

\section{Yuki Enomoto}

University of Tsukuba Faculty of Medicine: Tsukuba Daigaku Igaku Iryokei

Masao Iwagami ( $\square$ iwagami-tky@umin.ac.jp )

University of Tsukuba

\section{Asuka Tsuchiya}

University of Tokyo: Tokyo Daigaku

\section{Kojiro Morita}

University of Tsukuba Faculty of Medicine: Tsukuba Daigaku Igaku Iryokei

\section{Toshikazu Abe}

University of Tsukuba Faculty of Medicine: Tsukuba Daigaku Igaku Iryokei

\section{Takahiro Kido}

University of Tsukuba Faculty of Medicine: Tsukuba Daigaku Igaku Iryokei

\section{Kazuaki Uda}

University of Tokyo: Tokyo Daigaku

\section{Ryota Inokuchi}

University of Tsukuba Faculty of Medicine: Tsukuba Daigaku Igaku Iryokei

\section{Hideo Yasunaga}

University of Tokyo: Tokyo Daigaku

\section{Yoshiaki Inoue}

University of Tsukuba Faculty of Medicine: Tsukuba Daigaku Igaku Iryokei

Nanako Tamiya

University of Tsukuba Faculty of Medicine: Tsukuba Daigaku Igaku Iryokei

\section{Research}

Keywords: burns, dexmedetomidine, sedative, mechanical ventilation, mortality

Posted Date: December 11th, 2020

DOI: https://doi.org/10.21203/rs.3.rs-125444/v1

License: (c) (i) This work is licensed under a Creative Commons Attribution 4.0 International License. Read Full License

Version of Record: A version of this preprint was published at Burns on May 1st, 2021. See the published version at https://doi.org/10.1016/j.burns.2021.05.003. 


\section{Abstract}

Background: Dexmedetomidine is an alpha 2-adrenergic receptor agonist. Apart from its sedative effects, dexmedetomidine has the potential to reduce mortality through its anti-inflammatory effect. However, the impact of dexmedetomidine on in-hospital outcomes of patients with severe burns remains unclear. Therefore, we aimed to elucidate the association between dexmedetomidine and mortality in mechanically-ventilated patients with severe burns, using a Japanese nationwide database of in-hospital patients.

Methods: We included adults with severe burns (burn index $\geq 10$ ) who were registered in the Japanese Diagnosis Procedure Combination national inpatient database from 2010 to 2018, started mechanical ventilation within 3 days of admission, and received any sedative drug (dexmedetomidine, midazolam, or propofol). One-to-one propensity score matching was performed between patients who received dexmedetomidine on the day of mechanical ventilation initiation (dexmedetomidine group) and those who did not receive dexmedetomidine (control group). The primary outcome was all-cause 30-day in-hospital mortality. Secondary outcomes were length of hospital stay and duration of mechanical ventilation in all patients and survivors.

Results: Eligible patients ( $n=1,888)$ were classified into the dexmedetomidine group $(n=371)$ or the control group ( $n=$ 1,517). After one-to-one propensity score matching, we compared 329 patients from each of the two groups. No significant difference was observed in 30-day mortality between patients in the dexmedetomidine and control groups (22.8\% vs. $22.5 \%$, respectively; odds ratio, $1.02 ; 95 \%$ confidence interval, $0.71-1.46)$. Moreover, there were no significant differences between patients in the dexmedetomidine and control groups in terms of the length of hospital stay or the duration of mechanical ventilation.

Conclusions: We found no significant association between dexmedetomidine use and in-hospital outcomes (mortality, length of hospital stay, and length of mechanical ventilation) in mechanically-ventilated patients with severe burns. Dexmedetomidine use may not improve the above-mentioned outcomes; therefore, its selection should be based on the patient's general condition and the target level of sedation.

\section{Background}

Burns constitute a major cause of trauma. Although the mortality from burns is improving in developed countries, it remains high, at about $20 \%$, in patients with a total burn surface area of at least $20 \%$ [1-3]

Dexmedetomidine is an alpha 2-adrenergic receptor agonist that inhibits the release of endogenous noradrenalin. It is primarily used as a sedative for controlling critically ill patients into a good quality, light sedative state compared to midazolam and propofol [4]. Compared to benzodiazepines, dexmedetomidine has a more considerable effect in delirium risk reduction [5]. A few reports have examined the effects of dexmedetomidine on sedation and delirium in patients with burns [6-8].

In addition to its sedative effects, several studies have reported better outcomes with dexmedetomidine among critically ill patients compared to those of other sedative agents [9]. A systematic review of 1624 patients showed that the use of dexmedetomidine was associated with a reduction in the length of intensive care unit (ICU) stay and with mechanical ventilation use [9]. However, the impact of dexmedetomidine on short-term outcomes in patients with severe burns remains unclear $[4,10]$.

Dexmedetomidine is also expected to improve burn outcomes due to its anti-inflammatory effects [10, 11]. However, to our knowledge, no studies have examined a possible association between dexmedetomidine and mortality in patients with severe burns. Therefore, we aimed to investigate a possible association between dexmedetomidine use and 
mortality in mechanically-ventilated patients with severe burn, using a Japanese nationwide database of in-hospital patients.

\section{Methods}

\section{Data source}

We used the Japanese Diagnosis Procedure Combination database, which has been used for clinical studies on various topics, including burns [13-17]. The database contains discharge abstracts and administrative billing data from more than 1,000 voluntary participating hospitals in Japan. Until 2010, annual data were collected over a sixmonth period, from July 1 to December 31. Since 2011, data have been collected on a year-round basis. Larger hospitals were more likely to contribute their data to the database, with all 82 hospitals being academic; more than $90 \%$ of tertiary emergency hospitals were in the database, and $\$ 90 \%(90 / 100)$ of institutions were board-certified by the Japanese Society for Burn Injuries to impart training to burn specialists [13].

The dataset includes hospital identification number, hospital academic status, patient demographic characteristics, admission and discharge dates, main and comorbid diagnoses at admission, in-hospital complications (which were coded according to the International Classification of Diseases [ICD-10]), discharge status, procedure or operation dates and codes (in Japanese), and prescribed medications. Physicians attended to patient records to establish diagnoses at discharge. In order to optimise the accuracy of the recorded diagnosis, the attending physician was obligated to record the diagnosis with reference to the medical record.

Moreover, the database includes burn indices, which are calculated using both burn surface area and thickness: burn index $=$ full thickness of total burn surface area $+1 / 2$ partial thickness of total burn surface area $[13,18]$. Previous reports suggested that the burn index was a good predictor of patient mortality $[13,19]$.

\section{Study Participants}

We included patients aged 15 years or older, with emergency hospitalisation for burns (based on ICD-10 codes T20T30) between July 2010 and March 2018, who started mechanical ventilation within 3 days of admission, and were administered at least one of the following sedative agents: dexmedetomidine, midazolam, or propofol $[4,16,20]$. In addition, we restricted the study participants to patients with severe burns, defined as burn index $\geq 10[3,14,15]$. We excluded patients with missing records of burn index, and those who died on the day of mechanical ventilation initiation to avoid immortal time bias.

\section{Exposure}

The exposure of interest was the use of dexmedetomidine. The dexmedetomidine group was made of patients who were administered dexmedetomidine on the day of mechanical ventilation initiation, whereas the control group was made of patients who were administered either propofol or midazolam on the day of mechanical ventilation initiation. A small number of patients receiving both dexmedetomidine and propofol or midazolam were included in the dexmedetomidine group since our interest was the effect of dexmedetomidine.

\section{Outcomes}


The primary outcome was all-cause 30-day in-hospital mortality. Secondary outcomes included length of hospital stay and duration of mechanical ventilation in all patients and survivors.

\section{Covariates}

We considered the following characteristics as potential confounding factors: age; sex; body mass index; Charlson comorbidity index; burn index; the presence of inhalation injury and head/neck burns; Japan Coma Scale score at admission; hospital characteristics, including academic/non-academic status, the presence or absence of certification by the Japanese Society for Burn Injuries, and hospital volume; ICU admission; transportation from another hospital; and mechanical ventilation initiation day (i.e., day 0, 1, 2, or 3). Furthermore, we considered the following treatment regimens on the day of mechanical ventilation initiation: the use of other sedatives (propofol and midazolam), opioids, vasoactive agents (dopamine, dobutamine, adrenaline, noradrenaline, and vasopressin), albumin, intravenous antibiotics, transfusion (red blood cells, platelets, and fresh frozen plasma), continuous renal replacement therapy, enteral tube feeding, and surgery.

The body mass index, calculated using the formula: body mass index = mass (in $\mathrm{kg}$ )/height squared (in $\mathrm{m}^{2}$ ), was categorized into four groups: $<18.5,18.5$ to $<25,25$ to $<30$, and $\geq 30 \mathrm{~kg} / \mathrm{m}^{2}$ [21]. The Charlson comorbidity index reflects the underlying disease or condition [22], and is defined based on ICD-10 codes recorded in the database [23]. In this study, Charlson comorbidity index was categorised into three groups as follows: low, 0; medium, 1; and high, $\geq 2$. The Japan Coma Scale score is used to assess the level of consciousness, and correlates with the Glasgow Coma Scale score. Neurologic dysfunction scored at 100 points on the Japan Coma Scale is equivalent to scores of 6-9 on the Glasgow Coma Scale [24]. We categorised the Japan Coma Scale scores into four groups: 0, alert; 1-3, delirium; 10-30, \somnolence; and 100-300, coma. Hospital volume was defined as the number of patients with severe burns admitted per year during the study period and was categorised into low, medium, and high hospital volume. Hospital types were categorised based on the accreditation status issued by the Japanese Society for Burn Injuries.

\section{Statistical analysis}

We evaluated baseline characteristics and crude 30-day in-hospital mortality in the dexmedetomidine and control groups. Continuous and ordinal variables were expressed as medians and interquartile ranges. Categorical variables were presented as numbers and percentages. Comparisons were performed using the t-test for continuous variables and chi-squared test for categorical variables.

We conducted a one-to-one propensity score matched analysis to determine the conditional probability or the likelihood of administering dexmedetomidine using measured pre-treatment factors. The propensity score was estimated using a multivariable logistic regression model that adjusted for the aforementioned covariates (i.e., patient characteristics including age, squared terms of age, sex, comorbidities, degree of burn, consciousness; hospital characteristics and treatment regimen on the day of mechanical ventilation initiation). Each patient in the dexmedetomidine group was matched to a patient in the control group using nearest-neighbour matching, a calliper width equal to 0.2 of the standard deviation of the propensity score, and without replacement. The $\mathrm{C}$-statistic was calculated to evaluate the discriminative ability of the propensity score estimation. We used the standardized difference to measure covariate balance, whereby an absolute standardized difference $>10 \%$ represented meaningful imbalance [25].

In the propensity score-matched patients, we performed logistic regression analyses fitted with generalised estimating equations and paired t-tests to examine the association between dexmedetomidine use and 30-day mortality, as well as 
the length of hospital stay and the duration of mechanical ventilation in all eligible patients and survivors (to account for competing risk of death) [25].

We also conducted several sensitivity analyses. In the first sensitivity analysis, we used the inverse probability of treatment weighting (IPTW) method. First, we estimated the propensity score of receiving dexmedetomidine using the aforementioned covariates. Thereafter, we calculated the inverse probability of treatment. Finally, we estimated the effect of dexmedetomidine use on 30-day in-hospital mortality using a generalised linear model with a logit link function for a binomial outcome weighted by IPTW $[26,27]$. In the second sensitivity analysis, the outcome definition was changed to all cause in-hospital mortality.

In the third sensitivity analysis, we judged the exposure status (the use or non-use of dexmedetomidine) on the day of or the day following mechanical ventilation initiation. For this analysis, we excluded patients who died on the day of or day following mechanical ventilation initiation to avoid immortal time bias.

All tests of significance were two-tailed, and $p<.05$ was considered significant. Variables were analysed using Stata version 15 (Stata-Corp, College Station, TX, USA).

\section{Results}

We included 1,888 eligible patients, including 371 and 1,517 patients in the dexmedetomidine and control groups, respectively (Fig. 1). Patients in both groups had similar ages and sexes; however, those in the dexmedetomidine group had a lower burn index, and were more likely to receive catecholamines (dopamine, adrenalin, and noradrenalin) than those in the control group (Table 1, left columns). The crude 30 -day mortality was $24.3 \%(90 / 371)$ in the dexmedetomidine group and $28.0 \%$ (425/1517) in the control group. 
Table 1

Characteristics of the patients $\square$ before and after propensity score matching

\begin{tabular}{|c|c|c|c|c|c|c|}
\hline & \multicolumn{3}{|l|}{ Crude } & \multicolumn{3}{|c|}{ propensity score matched } \\
\hline & $\begin{array}{l}\text { Dexmedetomidine } \\
(\mathrm{N}=371)\end{array}$ & $\begin{array}{l}\text { Control } \\
(\mathrm{N}= \\
1517)\end{array}$ & $\begin{array}{l}\text { Standardized } \\
\text { difference } \\
(\%)\end{array}$ & $\begin{array}{l}\text { Dexmedetomidine } \\
(\mathrm{N}=329)\end{array}$ & $\begin{array}{l}\text { Control } \\
(\mathrm{N}= \\
329)\end{array}$ & $\begin{array}{l}\text { Standardized } \\
\text { difference } \\
(\%)\end{array}$ \\
\hline $\begin{array}{l}\text { Sex (male), n } \\
(\%)\end{array}$ & $226(60.9)$ & $\begin{array}{l}953 \\
(62.8)\end{array}$ & -1.5 & $204(62)$ & $\begin{array}{l}211 \\
(64.1)\end{array}$ & -4.4 \\
\hline $\begin{array}{l}\text { Age (year), } \\
\text { median (IQQR) }\end{array}$ & $67(51-79)$ & $\begin{array}{l}64 \\
(48- \\
77)\end{array}$ & 16.3 & $67(51-79)$ & $\begin{array}{l}66 \\
(49- \\
78)\end{array}$ & 10.7 \\
\hline Burn index & $22.5(15.0-36.0)$ & $\begin{array}{l}27.0 \\
(17.5- \\
42.5)\end{array}$ & -28.7 & $21.0(15.0-35.5)$ & $\begin{array}{l}22.0 \\
(16.0- \\
34.5)\end{array}$ & -2.3 \\
\hline $\begin{array}{l}\text { Inhalation } \\
\text { injury, n (\%) }\end{array}$ & $140(37.7)$ & $\begin{array}{l}556 \\
(36.7)\end{array}$ & 4.0 & $125(38)$ & $\begin{array}{l}134 \\
(40.7)\end{array}$ & -5.6 \\
\hline $\begin{array}{l}\text { Facial burn, } \\
\mathrm{n}(\%)\end{array}$ & $103(27.8)$ & $\begin{array}{l}349 \\
(23)\end{array}$ & 15.3 & $98(29.8)$ & $\begin{array}{l}106 \\
(32.2)\end{array}$ & -5.3 \\
\hline $\begin{array}{l}\text { Body mass } \\
\text { index, } \mathrm{n}(\%)\end{array}$ & & & 0.0 & & & 0.0 \\
\hline $18.5-25$ & $198(53.4)$ & $\begin{array}{l}801 \\
(52.8)\end{array}$ & 0.5 & $198(60.2)$ & $\begin{array}{l}194 \\
(59)\end{array}$ & 2.5 \\
\hline$<18,5$ & $32(8.6)$ & $\begin{array}{l}172 \\
(11.3)\end{array}$ & -10.0 & $32(9.7)$ & $\begin{array}{l}36 \\
(10.9)\end{array}$ & -4.0 \\
\hline $25-30$ & 70 (18.9) & $\begin{array}{l}261 \\
(17.2)\end{array}$ & 4.3 & $70(21.3)$ & $\begin{array}{l}74 \\
(22.5)\end{array}$ & -2.9 \\
\hline $30<$ & $29(7.8)$ & $\begin{array}{l}102 \\
(6.7)\end{array}$ & 4.3 & $29(8.8)$ & $\begin{array}{l}25 \\
(7.6)\end{array}$ & 4.4 \\
\hline $\begin{array}{l}\text { Charlson } \\
\text { Comorbidity } \\
\text { Index, } \mathrm{n}(\%)\end{array}$ & & & 0.0 & & & 0.0 \\
\hline 0 & 332 (89.5) & $\begin{array}{l}1398 \\
(92.2)\end{array}$ & -7.1 & $296(90)$ & $\begin{array}{l}300 \\
(91.2)\end{array}$ & -4.2 \\
\hline 1 & $7(1.9)$ & $\begin{array}{l}33 \\
(2.2)\end{array}$ & -4.8 & $5(1.5)$ & $5(1.5)$ & 0.0 \\
\hline$\geq 2$ & $32(8.6)$ & $\begin{array}{l}86 \\
(5.7)\end{array}$ & 10.4 & $28(8.5)$ & $\begin{array}{l}24 \\
(7.3)\end{array}$ & 4.5 \\
\hline $\begin{array}{l}\text { Japan Coma } \\
\text { Scale,n (\%) }\end{array}$ & & & 0.0 & & & 0.0 \\
\hline
\end{tabular}

IQR interquartile range, Burn index $=$ full thickness of total burn-surface area $+1 / 2$ partial thickness of total burnsurface area. Body mass index was categorized into four groups: $<18.5,18.5$ to $<25,25$ to $<30$ and $\geq 30$. The Charlson Comorbidity Index was categorized into the three groups in the current study as follows: low, 0; medium, 1 ; and high, >2. The Japan Coma Scale score was categorized into four groups: 0, alert; 1-3,delirium; 10-30, Isomnolence; and 100-300, coma. Hospital volume was defined as the number of patients with severe burn (burn index $>10$ ) admitted within the study period, categorized into tertiles (e.g., low, medium and high). 


\begin{tabular}{|c|c|c|c|c|c|c|}
\hline & Crude & & & propensity s & tched & \\
\hline clear & 161 (43.4) & $\begin{array}{l}558 \\
(36.8)\end{array}$ & 10.9 & $142(43.2)$ & $\begin{array}{l}140 \\
(42.6)\end{array}$ & 1.2 \\
\hline delirium & $93(25.1)$ & $\begin{array}{l}380 \\
(25)\end{array}$ & 2.1 & $85(25.8)$ & $\begin{array}{l}95 \\
(28.9)\end{array}$ & -6.8 \\
\hline somnolence & 41 (11.1) & $\begin{array}{l}166 \\
(10.9)\end{array}$ & -1.7 & 35 (10.6) & $\begin{array}{l}35 \\
(10.6)\end{array}$ & 0.0 \\
\hline coma & $76(20.5)$ & $\begin{array}{l}413 \\
(27.2)\end{array}$ & -13.7 & $67(20.4)$ & $\begin{array}{l}59 \\
(17.9)\end{array}$ & 6.2 \\
\hline $\begin{array}{l}\text { Interhospital } \\
\text { transfer, n } \\
(\%)\end{array}$ & $100(27)$ & $\begin{array}{l}348 \\
(22.9)\end{array}$ & 7.0 & 87 (26.4) & $\begin{array}{l}87 \\
(26.4)\end{array}$ & 0.0 \\
\hline $\begin{array}{l}\text { ICU } \\
\text { admission, n } \\
(\%)\end{array}$ & $275(74.1)$ & $\begin{array}{l}1119 \\
(73.8)\end{array}$ & -0.2 & $243(73.9)$ & $\begin{array}{l}246 \\
(74.8)\end{array}$ & -2.1 \\
\hline $\begin{array}{l}\text { Hospital } \\
\text { volume, n } \\
\text { (\%) }\end{array}$ & & & 0.0 & & & 0.0 \\
\hline Low & $103(27.8)$ & $\begin{array}{l}370 \\
(24.4)\end{array}$ & 11.4 & $88(26.7)$ & $\begin{array}{l}83 \\
(25.2)\end{array}$ & 3.5 \\
\hline Middle & $154(41.5)$ & $\begin{array}{l}490 \\
(32.3)\end{array}$ & 15.4 & $132(40.1)$ & $\begin{array}{l}140 \\
(42.6)\end{array}$ & -4.9 \\
\hline High & $114(30.7)$ & $\begin{array}{l}657 \\
(43.3)\end{array}$ & -25.4 & $109(33.1)$ & $\begin{array}{l}106 \\
(32.2)\end{array}$ & 1.9 \\
\hline $\begin{array}{l}\text { Academic } \\
\text { hospital, } n \\
(\%)\end{array}$ & $180(48.5)$ & $\begin{array}{l}724 \\
(47.7)\end{array}$ & 2.4 & $164(49.8)$ & $\begin{array}{l}168 \\
(51.1)\end{array}$ & -2.4 \\
\hline $\begin{array}{l}\text { Burn society } \\
\text { certified } \\
\text { hospital, n } \\
(\%)\end{array}$ & $172(46.4)$ & $\begin{array}{l}690 \\
(45.5)\end{array}$ & 2.2 & $154(46.8)$ & $\begin{array}{l}155 \\
(47.1)\end{array}$ & 0.6 \\
\hline $\begin{array}{l}\text { Initial day of } \\
\text { mechanical } \\
\text { ventilation }\end{array}$ & & & 0.0 & & & 0.0 \\
\hline 1 & $280(75.5)$ & $\begin{array}{l}1240 \\
(81.7)\end{array}$ & -17.1 & $246(74.8)$ & $\begin{array}{l}248 \\
(75.4)\end{array}$ & -1.4 \\
\hline 2 & 59 (15.9) & $\begin{array}{l}208 \\
(13.7)\end{array}$ & 7.4 & $53(16.1)$ & $\begin{array}{l}52 \\
(15.8)\end{array}$ & 0.8 \\
\hline 3 & $32(8.6)$ & $\begin{array}{l}69 \\
(4.5)\end{array}$ & 17.4 & $30(9.1)$ & $\begin{array}{l}29 \\
(8.8)\end{array}$ & 1.1 \\
\hline
\end{tabular}

$I Q R$ interquartile range, Burn index $=$ full thickness of total burn-surface area $+1 / 2$ partial thickness of total burnsurface area. Body mass index was categorized into four groups: $<18.5,18.5$ to $<25,25$ to $<30$ and $\geq 30$. The Charlson Comorbidity Index was categorized into the three groups in the current study as follows: low, 0; medium, 1; and high, $>2$. The Japan Coma Scale score was categorized into four groups: 0 , alert; 1-3,delirium; 10-30, पsomnolence; and 100-300, coma. Hospital volume was defined as the number of patients with severe burn (burn index $>10$ ) admitted within the study period, categorized into tertiles (e.g., low, medium and high). 


\begin{tabular}{|c|c|c|c|c|c|c|}
\hline \multicolumn{3}{|c|}{ Crude } & \multicolumn{4}{|c|}{ propensity score matched } \\
\hline $\begin{array}{l}\text { Propofol, n } \\
\text { (\%) }\end{array}$ & $226(60.9)$ & $\begin{array}{l}904 \\
(59.6)\end{array}$ & -1.7 & $193(58.7)$ & $\begin{array}{l}202 \\
(61.4)\end{array}$ & -5.6 \\
\hline $\begin{array}{l}\text { Midazolam, } \\
\text { n (\%) }\end{array}$ & $166(44.7)$ & $\begin{array}{l}1027 \\
(67.7)\end{array}$ & -44.8 & $150(45.6)$ & $\begin{array}{l}162 \\
(49.2)\end{array}$ & -7.3 \\
\hline Opioid, n (\%) & 318 (85.7) & $\begin{array}{l}1209 \\
(79.7)\end{array}$ & 12.2 & $279(84.8)$ & $\begin{array}{l}280 \\
(85.1)\end{array}$ & -0.8 \\
\hline $\begin{array}{l}\text { Antibiotics, n } \\
(\%)\end{array}$ & $232(62.5)$ & $\begin{array}{l}804 \\
(53)\end{array}$ & 18.9 & $206(62.6)$ & $\begin{array}{l}201 \\
(61.1)\end{array}$ & 3.1 \\
\hline $\begin{array}{l}\text { Dopamine, n } \\
(\%)\end{array}$ & $77(20.8)$ & $\begin{array}{l}192 \\
(12.7)\end{array}$ & 23.2 & $68(20.7)$ & $\begin{array}{l}68 \\
(20.7)\end{array}$ & 0.0 \\
\hline $\begin{array}{l}\text { Dobutamine, } \\
\text { n (\%) }\end{array}$ & $19(5.1)$ & $\begin{array}{l}67 \\
(4.4)\end{array}$ & 4.0 & $16(4.9)$ & $\begin{array}{l}17 \\
(5.2)\end{array}$ & -1.4 \\
\hline $\begin{array}{l}\text { Adrenalin, } \mathrm{n} \\
(\%)\end{array}$ & $40(10.8)$ & $75(4.9)$ & 22.9 & $37(11.2)$ & $\begin{array}{l}29 \\
(8.8)\end{array}$ & 8.1 \\
\hline $\begin{array}{l}\text { Noradrenalin, } \\
\mathrm{n}(\%)\end{array}$ & $130(35)$ & $\begin{array}{l}229 \\
(15.1)\end{array}$ & 41.5 & $107(32.5)$ & $\begin{array}{l}102 \\
(31)\end{array}$ & 3.3 \\
\hline $\begin{array}{l}\text { Vasopressin, } \\
\text { n (\%) }\end{array}$ & $5(1.3)$ & $\begin{array}{l}18 \\
(1.2)\end{array}$ & -2.8 & $3(0.9)$ & $5(1.5)$ & -5.5 \\
\hline $\begin{array}{l}\text { Albumin, } \mathrm{n} \\
(\%)\end{array}$ & $167(45)$ & $\begin{array}{l}604 \\
(39.8)\end{array}$ & 7.1 & $143(43.5)$ & $\begin{array}{l}145 \\
(44.1)\end{array}$ & -1.2 \\
\hline $\begin{array}{l}\text { Blood } \\
\text { transfusion, } \\
n(\%)\end{array}$ & $38(10.2)$ & $\begin{array}{l}131 \\
(8.6)\end{array}$ & 5.1 & $34(10.3)$ & $33(10)$ & 1.0 \\
\hline $\begin{array}{l}\text { continuous } \\
\text { renal } \\
\text { replacement } \\
\text { therapy, } n \\
(\%)\end{array}$ & $14(3.8)$ & $\begin{array}{l}67 \\
(4.4)\end{array}$ & -6.2 & $10(3)$ & $\begin{array}{l}19 \\
(5.8)\end{array}$ & -13.0 \\
\hline $\begin{array}{l}\text { Enteral } \\
\text { nutrition, n } \\
(\%)\end{array}$ & $95(25.6)$ & $\begin{array}{l}297 \\
(19.6)\end{array}$ & 12.6 & $85(25.8)$ & $\begin{array}{l}82 \\
(24.9)\end{array}$ & 2.1 \\
\hline $\begin{array}{l}\text { Skin graft } \\
\text { surgery or } \\
\text { debridement, } \\
\mathrm{n}(\%)\end{array}$ & $38(10.2)$ & $\begin{array}{l}105 \\
(6.9)\end{array}$ & 12.4 & $35(10.6)$ & $\begin{array}{l}37 \\
(11.2)\end{array}$ & -1.9 \\
\hline $\begin{array}{l}\text { IQR interquarti } \\
\text { surface area. } \\
\text { Charlson Com } \\
\text { and high, > } 2 \text {. } \\
\text { lsomnolence; } \\
\text { index }>10 \text { ) adr }\end{array}$ & $\begin{array}{l}\text { range, Burn } \\
\text { ody mass ind } \\
\text { rbidity Index } \\
\text { he Japan Cor } \\
\text { nd } 100-300, \\
\text { iitted within } t\end{array}$ & $\begin{array}{l}\text { Il thickn } \\
\text { tegorize } \\
\text { yorized ir } \\
\text { score wa } \\
\text { spital vc } \\
\text { jeriod, ca }\end{array}$ & $\begin{array}{l}\text { S of to } \\
\text { into fo } \\
\text { b the th } \\
\text { categc } \\
\text { ime wo }\end{array}$ & $\begin{array}{l}\text { ce area }+1 / 2 \\
3.5,18.5 \text { to }< \\
\text { the current } \\
\text { r groups: } 0, \text { a } \\
\text { he number o } \\
\text { (e.g., low, me }\end{array}$ & $\begin{array}{l}\text { hickness c } \\
<30 \text { and } \\
\text { ollows: lo } \\
\text { delirium; } \\
\text { s with sev } \\
\text { d high). }\end{array}$ & $\begin{array}{l}\text { total burn- } \\
30 \text {. The } \\
0 ; \text { medium, } 1 \\
0-30 \text {, } \\
\text { re burn (burn }\end{array}$ \\
\hline
\end{tabular}

We matched 329 pairs according to the propensity score of receiving dexmedetomidine. The C-statistic was 0.737 . The covariates in the matched cohort were well balanced (Table 1, right columns). After propensity score matching, the 30day mortality was $22.8 \%(75 / 329)$ in the dexmedetomidine group and $22.5 \%(74 / 329)$ in the control group $(p=0.93)$. 
In the logistic regression analysis fitted with generalised estimating equations, dexmedetomidine administration was not associated with 30-day mortality (odds ratio, 1.02; 95\% confidence interval, 0.71-1.46) (Fig. 2). As for secondary outcomes, there $\mathbb{X}$ were no differences in the length of hospital stay in all patients (dexmedetomidine 52 days vs. control 49 days, $p=0.86$ ) and survivors (dexmedetomidine 73 days vs. control 78 days, $p=0.19$ ), akin to the duration of mechanical ventilation in all patients (dexmedetomidine 16 days vs. control 16 days, $p=0.27$ ) and survivors (dexmedetomidine 17 days vs. control 18 days, $p=0.18$ ) (Table 2 ).

Table 2

पStudy outcomes before and after propensity score matching

\begin{tabular}{|c|c|c|c|c|c|c|}
\hline & \multicolumn{3}{|l|}{ Crude } & \multicolumn{3}{|c|}{ Propensity score matched } \\
\hline & Dexmedetomidine & Control & \multirow{2}{*}{$\begin{array}{l}p- \\
\text { value }\end{array}$} & Dexmedetomidine & Control & \multirow{2}{*}{$\begin{array}{l}p- \\
\text { value }\end{array}$} \\
\hline & $(\mathrm{N}=371)$ & $\begin{array}{l}(\mathrm{N}= \\
1517)\end{array}$ & & $(N=329)$ & $\begin{array}{l}(\mathrm{N}= \\
329)\end{array}$ & \\
\hline $\begin{array}{l}\text { Length of stay (overall) day, } \\
\text { median (IQR) }\end{array}$ & $52(19-96)$ & $\begin{array}{l}49(13- \\
95)\end{array}$ & 0.86 & $54(20-101)$ & $\begin{array}{l}61 \\
(13- \\
95)\end{array}$ & 0.98 \\
\hline $\begin{array}{l}\text { Length of stay (survivors) } \\
\text { day, median (IQR) }\end{array}$ & $73(42-115)$ & $\begin{array}{l}78 \\
(45- \\
122)\end{array}$ & 0.19 & $74(46-116)$ & $\begin{array}{l}78 \\
(45- \\
122)\end{array}$ & 0.90 \\
\hline $\begin{array}{l}\text { Duration of mechanical } \\
\text { ventilation (overall) day, } \\
\text { median (IQR) }\end{array}$ & $16(6-36)$ & $\begin{array}{l}16(6- \\
38)\end{array}$ & 0.27 & $16(7-36)$ & $\begin{array}{l}16(7- \\
35)\end{array}$ & 0.69 \\
\hline $\begin{array}{l}\text { Duration of mechanical } \\
\text { ventilation (survivors) day, } \\
\text { median (IQR) }\end{array}$ & $17(7-36)$ & $\begin{array}{l}18(8- \\
40)\end{array}$ & 0.18 & $17(7-36)$ & $\begin{array}{l}15(8- \\
34)\end{array}$ & 0.65 \\
\hline 30-day mortality, n (\%) & $90(24.3)$ & $\begin{array}{l}425 \\
(28.0)\end{array}$ & 0.15 & $75(22.8)$ & $\begin{array}{l}73 \\
(22.2)\end{array}$ & 0.93 \\
\hline in-hospital mortality, n (\%) & $132(35.6)$ & $\begin{array}{l}621 \\
(40.9)\end{array}$ & 0.06 & $115(35)$ & $\begin{array}{l}112 \\
(34)\end{array}$ & 0.87 \\
\hline
\end{tabular}

The sensitivity analyses showed similar results with those of our main analysis (Fig. 2). In the first sensitivity analysis, the IPTW method resulted in an adjusted odds ratio of 0.98 (95\% confidence interval $0.69-1.39)$ for 30 -day mortality. In the second sensitivity analysis, the odds ratio (and 95\% confidence interval) of setting the outcome as the in-hospital mortality was $1.03(0.75-1.40)$. In the third sensitivity analysis, the odds ratio (and 95\% confidence interval) of judging the exposure status on the day of or day following mechanical ventilation initiation was 0.99 (0.70-1.38) (Fig. 2).

\section{Discussion}

Using a Japanese national in-hospital database, we examined the association between dexmedetomidine administration and in-hospital outcomes in mechanically-ventilated patients with severe burns. We found no significant differences between patients in the dexmedetomidine and control groups in terms of mortality, length of hospital stay, and duration of mechanical ventilation. Several sensitivity analyses led to the same conclusions.

A systematic review showed that dexmedetomidine administration was associated with a reduced duration of mechanical ventilation and hospital stay in ICU patients [9]. However, this result may not be applicable to patients with 
burns because previous studies often excluded patients with burns, and the systematic review did not specifically examine the effect of dexmedetomidine in patients with burns $[4,10]$.

Recently, several studies have examined the use of dexmedetomidine in patients with sepsis [20, 28-30]. A metaanalysis of observational studies and a secondary analysis of randomized control trials have shown significant differences in duration of ventilator-free days and short-term mortality $[28,29]$. An observational study also found a reduction in mortality and ventilation duration with dexmedetomidine use [20]. Nonetheless, randomized control trials have not shown prognosis improvements with dexmedetomidine use [30]. Therefore, the effect of dexmedetomidine on mortality remains inconclusive, even in sepsis.

We expected that dexmedetomidine could improve severe burn outcomes through sedation amelioration, delirium risk reduction [4, 31] and anti-inflammatory effects that are organo-protective [11, 12, 32-35]. However, in the current study, we did not find any benefit of dexmedetomidine in patients with severe burns for several possible reasons. First, burns are very heterogeneous. Mortality could be influenced by a variety of patient (burn severity and location) and hospital factors (the availability of specialists and equipment for severe burn management). In such situations, dexmedetomidine may play a relatively small role in saving patients' lives. Second, in Japan, the average hospital length of stay in an acute care hospital tends to be longer [36]. This may be driven by factors such as wound complexity and general management conditions, especially for burns. Social factors, rather than medical conditions, may play a role in the longer hospital length of stay [37], which may explain why there was no difference in the lengths of hospital stay. Third, the duration of mechanical ventilation may be influenced not only by systemic conditions but also by localised burn conditions (e.g., inhalation injury or facial injury) and surgery timing. These factors cannot be modified by dexmedetomidine.

\section{Limitation}

This study has several limitations. First, this was a retrospective cohort study, and therefore unmeasured or residual confounding factors could have masked the potential association between use dexmedetomidine use and in-hospital outcomes. Although we believe that we could adjust for important confounding factors (e.g., the combination of burn index and age, which have been reported to be valid outcome predictors in patients with burns [13]), there may be some outcome-predicting factors such as vital signs and blood test results. Second, if the effect of dexmedetomidine was small, we might not have been able to detect it with our sample size. Furthermore, subgroup analysis was not performed because of the small sample size. Thus, it remains a possibility that a small group of patients might benefit from dexmedetomidine. Finally, only in-hospital mortality was assessed in the present study. Post-discharge data were not available because the follow-up ended on the date of discharge. However, the overall mean length of hospital stay in the current study was approximately 50 days, and we believe the drug's impact on acute illness could be assessed within this timeframe.

\section{Conclusion}

Using a nationwide inpatient database in Japan, we did not find an association between dexmedetomidine and improved in-hospital outcomes (mortality, length of hospital stay, and length of mechanical ventilation) in mechanically-ventilated patients with severe burns. Thus, dexmedetomidine use may not be justified for the purpose of improving the aforementioned outcomes, and the choice of sedatives should depend on the patient's general condition and sedation target level. Further studies are warranted to elucidate the merits and demerits of dexmedetomidine in patients with severe burns. 


\section{Abbreviations}

ICU

intensive care unit

ICD-10

International Classification of Diseases

IPTW

inverse probability of treatment weighting

\section{Declarations}

\section{Ethics approval and consent to participate}

Patient identifiers were removed from this database. Informed consent was waived because patient data were anonymous, and the study was approved by the Institutional Review Board of the University of Tokyo.

\section{Consent for publication}

Not applicable

\section{Availability of data and materials}

The data that support the findings of this study are available from the Ministry of Health, Labour, and Welfare; however, these data were used under license for the current study, and therefore are not publicly available.

\section{Competing interests}

The authors declare that they have no competing interests.

\section{Funding}

The present study was supported by grants from the Ministry of Health, Labour, and Welfare, Japan (20K09261).

\section{Authors' contributions}

YE, MI, AT, KM, TA, and TK designed and conceived this study, performed statistical analysis, and edited the initial manuscript draft. TK, RI, HY, YI, and NT provided professional suggestions on the conduct of the study and interpretation of study results. $\mathrm{KU}$ contributed to data collection and management. All authors approved the final manuscript.

\section{Acknowledgements}

We would like to thank Editage for English language editing.

\section{References}

1. Mason SA, Nathens AB, Byrne JP, Gonzalez A, Fowler R, Karanicolas PJ, et al. Trends in the epidemiology of major burn injury among hospitalized patients: A population-based analysis. J Trauma Acute Care Surg. 2017;83:86774. 
2. National Burn Repository 2017 Update. https://cdn.ymaws.com/ameriburn.site-

ym.com/resource/collection/4C72F10C-24FD-401C-8608-417BFAB10138/2017_ABA_NBR_Annual_Report.pdf. Accessed 30 October 2020.

3. Endo A, Shiraishi A, Otomo Y, Fushimi K, Murata K. Volume-outcome relationship on survival and cost benefits in severe burn injury: a retrospective analysis of a Japanese nationwide administrative database. J Intensive Care. 2019;7:7.

4. Jakob SM. Dexmedetomidine vs Midazolam or Propofol for Sedation During Prolonged Mechanical Ventilation: Two Randomized Controlled Trials. JAMA. 2012;307:1151-60.

5. Pandharipande PP, Pun BT, Herr DL, Maze M, Girard TD, Miller RR, et al. Effect of Sedation With Dexmedetomidine vs Lorazepam on Acute Brain Dysfunction in Mechanically Ventilated Patients: The MENDS Randomized Controlled Trial. JAMA. 2007;298:2644-53.

6. Asmussen S, Maybauer DM, Fraser JF, Jennings K, George S, Maybauer MO. A meta-analysis of analgesic and sedative effects of dexmedetomidine in burn patients. Burns. 2013;39:625-31.

7. Jiang M, Sun Q, Liu G, Qu H, Ma J. Efficacy of dexmedetomidine in reducing post-operative pain and improving the quality of recovery in patients with burn wounds undergoing tangential excision skin grafting. Exp Ther Med. 2019;17:1776-82.

8. Fagin A, Palmieri T, Greenhalgh D, Sen S. A Comparison of Dexmedetomidine and Midazolam for Sedation in Severe Pediatric Burn Injury. J Burn Care Res. 2012;33:759-63.

9. Chen K, Lu Z, Xin YC, Cai Y, Chen Y, Pan SM. Alpha-2 agonists for long-term sedation during mechanical ventilation in critically ill patients. Cochrane Emergency and Critical Care Group, editor. Cochrane Database of Syst Rev. 2015(1) doi:10.1002/14651858.CD010269.pub2.

10. Shehabi Y, Bellomo R, Reade MC, Bailey M, Bass F, Howe B, et al. Early goal-directed sedation versus standard sedation in mechanically ventilated critically ill patients: a pilot study. Crit Care Med. 2013;41:1983-91.

11. Cassuto J, Tarnow P, Yregård L, Lindblom L, Räntfors J. Adrenoceptor subtypes in the control of burn-induced plasma extravasation. Burns. 2005;31:123-9.

12. Flanders CA, Rocke AS, Edwardson SA, Baillie JK, Walsh TS. The effect of dexmedetomidine and clonidine on the inflammatory response in critical illness: a systematic review of animal and human studies. Crit Care. 2019;23:402.

13. Tagami T, Matsui H, Fushimi K, Yasunaga H. Validation of the prognostic burn index: A nationwide retrospective study. Burns. 2015;41:1169-75.

14. Tagami T, Matsui H, Fushimi K, Yasunaga H. Prophylactic antibiotics may improve outcome in patients with severe burns requiring mechanical ventilation: propensity score analysis of a Japanese nationwide database. Clin Infect Dis. 2016;62:60-6.

15. Tagami T, Matsui H, Moroe Y, Fukuda R, Shibata A, Tanaka C, et al. Antithrombin use and 28-day in-hospital mortality among severe-burn patients: an observational nationwide study. Ann Intensive Care. 2017;7:18.

16. Tsuchiya A, Yamana H, Kawahara T, Tsutsumi Y, Matsui H, Fushimi K, et al. Tracheostomy and mortality in patients with severe burns: A nationwide observational study. Burns. 2018;44:1954-61.

17. Nakajima M, Kojiro M, Aso S, Matsui H, Fushimi K, Kaita Y, et al. Effect of high-dose vitamin C therapy on severe burn patients: a nationwide cohort study. Crit Care. 2019;23(1):1-8.

18. Sheppard NN, Hemington-Gorse S, Shelley OP, Philp B, Dziewulski P. Prognostic scoring systems in burns: A review. Burns. 2011;37:1288-95. 
19. Kobayashi K, Ikeda H, Higuchi R, Nozaki M, Yamamoto Y, Urabe M, et al. Epidemiological and outcome characteristics of major burns in Tokyo. Burns. 2005;31:3-11.

20. Aso S. Dexmedetomidine and mortality from sepsis requiring mechanical ventilation: a Japanese nationwide retrospective cohort study. J Int Care Med. 2020:0885066620942154.

21. WHO Consultation on Obesity. In: Obesity: preventing and managing the global epidemic : report of a WHO Consultation on Obesity, Geneva, 3-5 June 1997. World Health Organization. 1998.

https://apps.who.int/iris/handle/10665/63854 Accessed 30 Oct 2020.

22. Lundgren RS, Kramer CB, Rivara FP, Wang J, Heimbach DM, Gibran NS, et al. Influence of Comorbidities and Age on Outcome Following Burn Injury in Older Adults. J Burn Care Res. 2009;30:307-14.

23. Quan H, Li B, Couris CM, Fushimi K, Graham P, Hider P, et al. Updating and Validating the Charlson Comorbidity Index and Score for Risk Adjustment in Hospital Discharge Abstracts Using Data From 6 Countries. Am J Epidemiol. 2011;173:676-82.

24. Tagami T, Matsui H, Horiguchi H, Fushimi K, Yasunaga H. Antithrombin and mortality in severe pneumonia patients with sepsis-associated disseminated intravascular coagulation: an observational nationwide study. J Thromb Haemost. 2014;12:1470-9.

25. Austin PC. Propensity-score matching in the cardiovascular surgery literature from 2004 to 2006: A systematic review and suggestions for improvement. J Thorac Cardiovasc Surg. 2007;134:1128-35.

26. Hernán M, Brumback B, Robins JM. Marginal Structural Models to Estimate the Causal Effect of Zidovudine on the Survival of HIV-Positive Men. Epidemiology. 2000;11:561-70.

27. Robins JM, Hernán M, Brumback B. Marginal Structural Models and Causal Inference in Epidemiology. Epidemiology. 2000;11:550-60.

28. Zamani MM, Keshavarz-Fathi M, Fakhri-Bafghi MS, Hirbod-Mobarakeh A, Rezaei N, Bahrami A, et al. Survival benefits of dexmedetomidine used for sedating septic patients in intensive care setting: A systematic review. J Crit Care. 2016;32:93-100.

29. Pandharipande PP, Sanders RD, Girard TD, McGrane S, Thompson JL, Shintani AK, et al. Effect of dexmedetomidine versus lorazepam on outcome in patients with sepsis: an a priori-designed analysis of the MENDS randomized controlled trial. Crit Care. 2010;14(2):R38.

30. Kawazoe Y, Miyamoto K, Morimoto T, Yamamoto T, Fuke A, Hashimoto A, et al. Effect of dexmedetomidine on mortality and ventilator-free days in patients requiring mechanical ventilation with sepsis: a randomized clinical trial. JAMA. 2017;317:1321.

31. Ely EW. Delirium as a predictor of mortality in mechanically ventilated patients in the intensive care unit. JAMA. 2004;291:1753.

32. Taniguchi T, Kidani Y, Kanakura H, Takemoto Y, Yamamoto K. Effects of dexmedetomidine on mortality rate and inflammatory responses to endotoxin-induced shock in rats. Crit Care Med. 2004;32:1322-6.

33. Wilmore DW, Mason AD, Pruitt BA. Mediator of the Hypermetabolic Response to Thermal Injury. Ann Surg. 1974;180:653-68.

34. Schmittinger CA, Torgersen C, Luckner G, Schröder DCH, Lorenz I, Dünser MW. Adverse cardiac events during catecholamine vasopressor therapy: a prospective observational study. Int Care Med. 2012;38:950-8.

35. Sander O, Welters ID, Foëx P, Sear JW. Impact of prolonged elevated heart rate on incidence of major cardiac events in critically ill patients with a high risk of cardiac complications. Crit Care Med. 2005;33:81-8.

36. Average length of stay in hospitals | Health at a Glance 2019. OECD Indicators | OECD iLibrary. https://www.oecdilibrary.org/sites/0d8bb30a-en/index.html?itemld=/content/component/0d8bb30a-en Accessed 2 October 2020.

Page $13 / 17$ 
37. Tiessen J, Kambara H, Sakai T, Kato K, Yamauchi K, McMillan C. What causes international variations in length of stay: A comparative analysis for two inpatient conditions in Japanese and Canadian hospitals. Health Serv Manage Res. 2013;26:86-94.

\section{Figures}

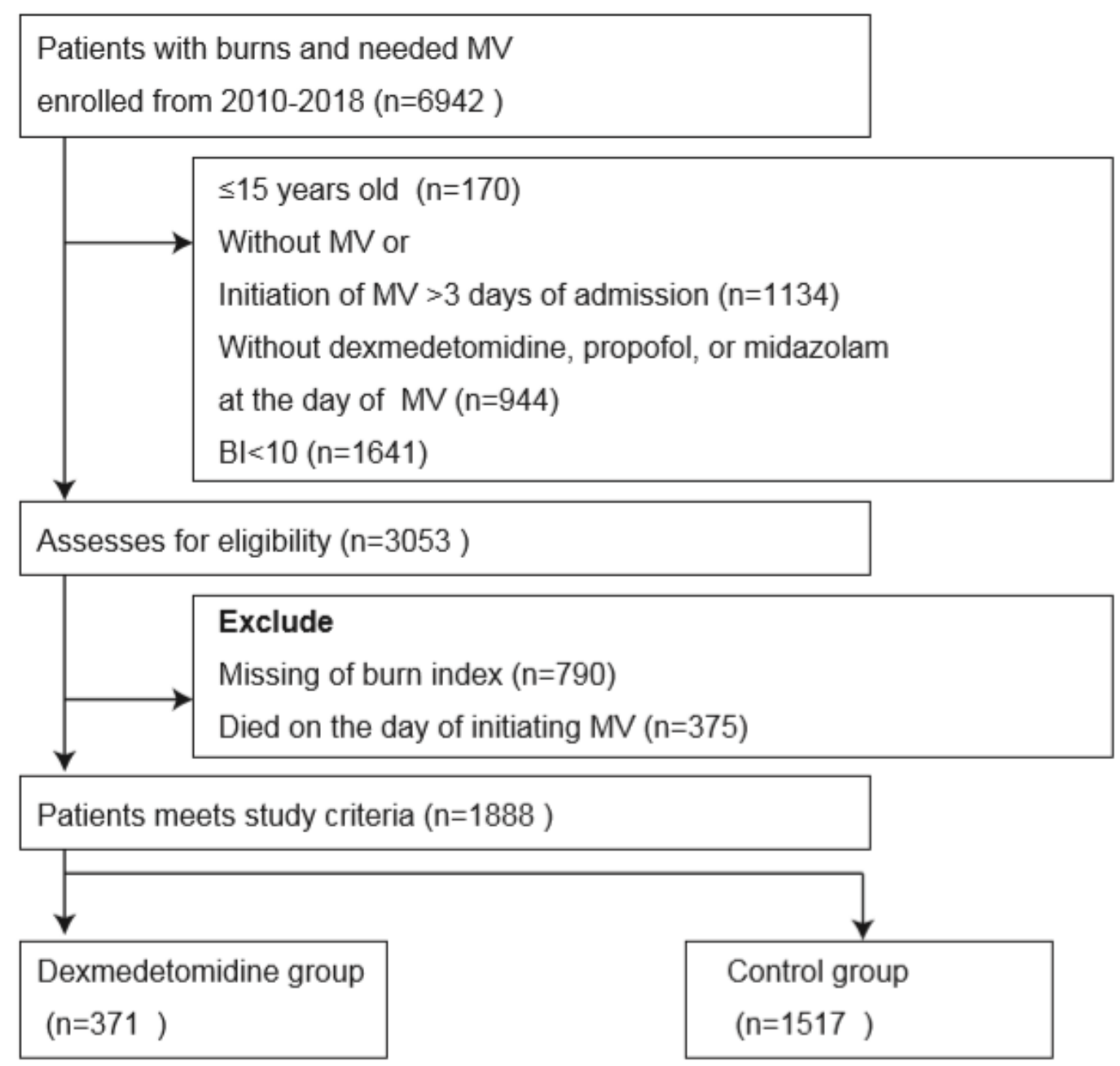

\section{Figure 1}

Outline of patient selection MV: mechanical ventilation 


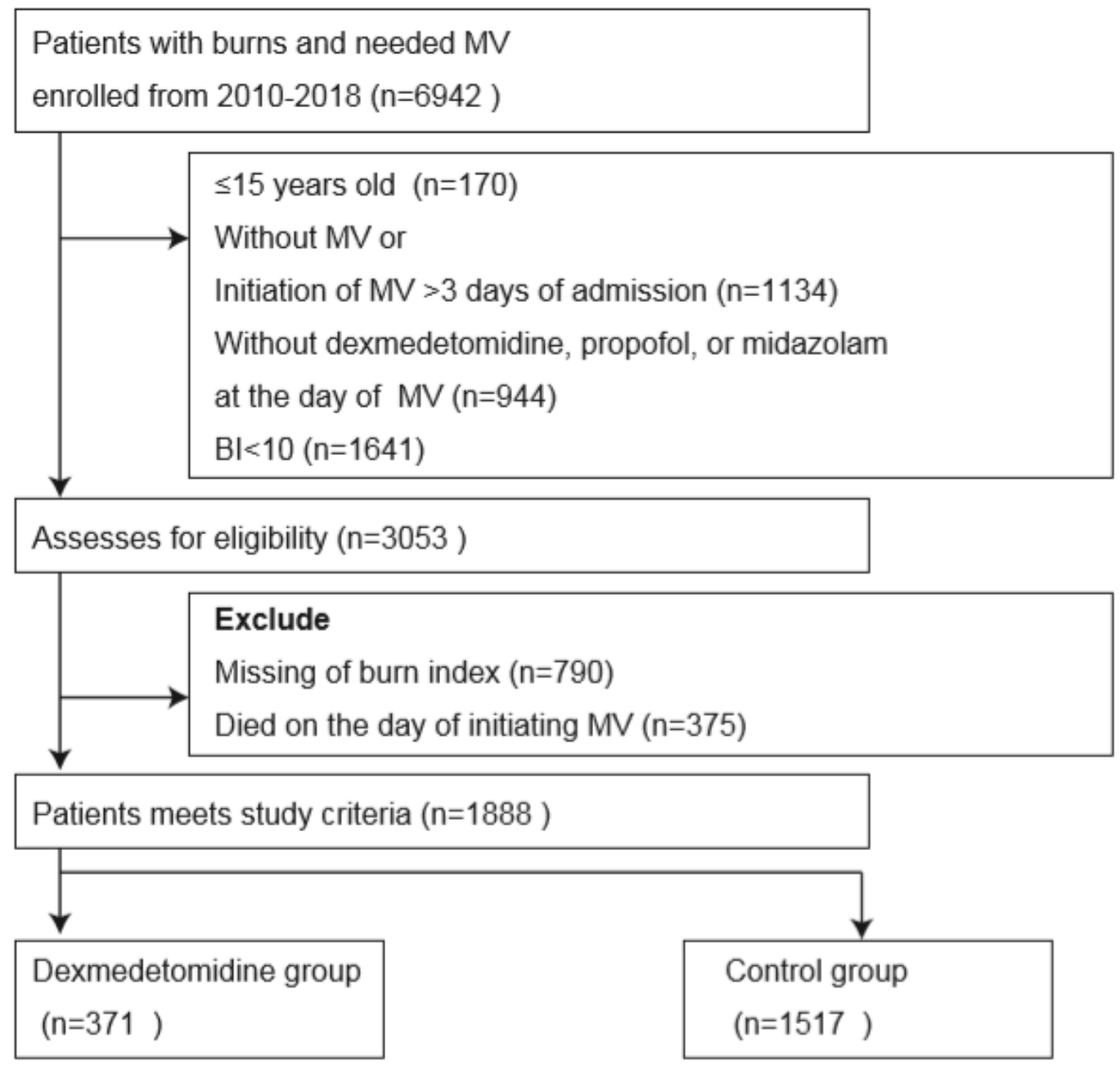

\section{Figure 1}

Outline of patient selection MV: mechanical ventilation 


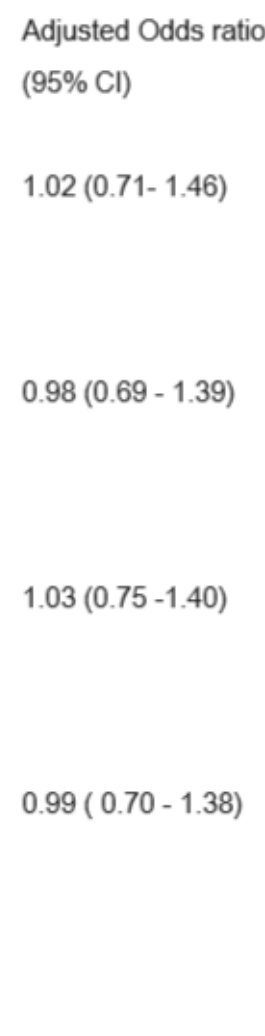

\section{Figure 2}

Thirty-day hospital mortality in patients in the dexmedetomidine and control groups and the result of sensitivity analysis PSM: propensity score matching, IPTW: inversed probability treatment weighting * We classified the exposure status (the use or non-use of dexmedetomidine) on the day of or day following mechanical ventilation initiation 


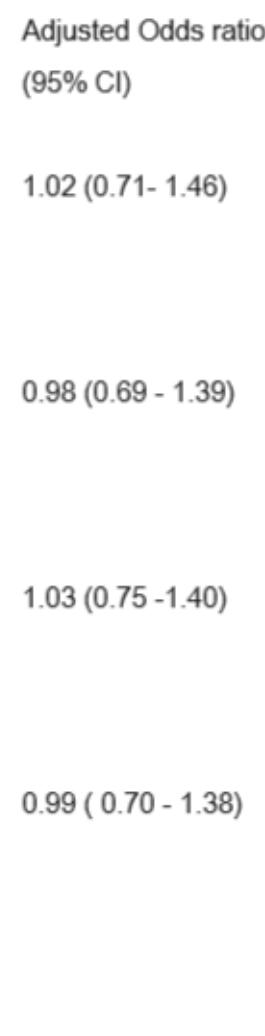

\section{Figure 2}

Thirty-day hospital mortality in patients in the dexmedetomidine and control groups and the result of sensitivity analysis PSM: propensity score matching, IPTW: inversed probability treatment weighting * We classified the exposure status (the use or non-use of dexmedetomidine) on the day of or day following mechanical ventilation initiation 